Topics in Health \& Biomedical Engineering (THBE) 1(1) (2018) 14-16

Contents List available at VOLKSON PRESS

Medical and Pharmaceutical Research (MPR)

DOI : http://doi.org/10.26480/wcmpr.01.2018.14.16

Journal Homepage: http://www.topicsonbiomed.com//

\title{
CLINICAL ANALYSIS OF ACUPUNCTURE THERAPY IN THE TREATMENT OF ARTHRITIS WITH TRADITIONAL CHINESE MEDICINE
}

\author{
Li Yunpeng ${ }^{1,2^{*}}$, Lu Hua ${ }^{1,2}$, Wu Shuang ${ }^{1,2}$, Xu Dayong ${ }^{1,2}$, Yue zongjin ${ }^{1,2}$, Wang Xinli ${ }^{1,2}$ \\ ${ }^{1}$ Henan Province Hospital of Traditional Chinese Medicine, 450002.Zhengzhou, 450000, Henan, P. R. China \\ ${ }^{2}$ The Second Affiliated Hospital of Henan University of Traditional Chinese Medicine, 450000, Henan, P. R. China \\ *Corresponding Author Email: 253863528@qq.com
}

This is an open access article distributed under the Creative Commons Attribution License, which permits unrestricted use, distribution, and reproduction in any medium, provided the original work is properly cited

\section{ARTICLE DETAILS}

\section{ARTICLE HISTORY:}

Received 2nd January 2018

Accepted 2nd January 2018

Available online 3rd January 2018

\section{KEYWORDS:}

arthritis patients, traditional Chinese medicine acupuncture treatment, clinical treatment, treatment effect

\begin{abstract}
With the aging of the population process, the incidence of arthritis was significantly increased, seriously endangering the health and quality of life of the elderly. The disease is multiple, the etiology is not clear, the current treatment of Western medicine, easy to produce adverse reactions to traditional Chinese medicine acupuncture treatment can often achieve very good results. METHODS: The clinical data of 86 patients treated with arthritis from March 2017 to June 2017 were retrospectively analyzed. Our hospital according to the random number table method to these 86 patients were divided into control group and treatment group, each group had 43 patients. Our hospital in the control group of patients with conventional Western medicine treatment, the observation group of patients in the treatment of Western medicine based on the use of acupuncture treatment, and then compare the treatment of the two groups of patients. Results: After two groups of patients were treated, the number of tender joints, tenderness index, swelling joint number, average grip strength, morning stiffness time and pain intensity score were significantly lower in the observation group than those in the control group before and after treatment. The treatment effect was significant $(\mathrm{P}<0.05)$, with statistical significance, in order to better promote the application.
\end{abstract}

\section{INTRODUCTION}

Arthritis is a common bone and joint disease, the main pathological changes in articular cartilage degenerative changes, involving the bone, synovium, joint capsule and other structures of the chronic aseptic inflammation, localized articular cartilage destruction and joint edge Osteophyte formation [1]. Knee osteoarthritis progress slowly, eventually leading to joint dysfunction, knee pain, swelling, stiffness, dysfunction as the main clinical manifestations. At present, there are many ways to treat this disease, Western medicine and oral administration of intra-articular drug therapy or arthroscopy, joint replacement and other surgical treatment, although the disease has a certain effect, but the effect is poor, high cost, and toxic side effects The Traditional Chinese medicine in the treatment of arthritis has shown a certain advantage, such as traditional Chinese medicine oral administration of acupuncture and massage, cupping and thorn bloodletting on different syndromes of arthritis have a better effect, you can quickly relieve knee pain Swelling, improve knee activity [2]. And easy to operate, safe, low economic costs, non-toxic side effects. With the increase in the incidence of this disease, the effective treatment of the disease needs of the disease will become increasingly large, Chinese medicine, especially acupuncture in the treatment of this disease has irreplaceable superiority.

Knee is the largest and most complex articular in the human body. Its components include the lower end of the femur, the upper part of the tibia and the bones, and the three together form the elliptical spine joint. The proximal femur and tibial proximal surface covered cartilage as shown in Fig1. The articular cartilage itself is elastic, as the lowest coefficient of friction material, it can even distribute the force, expand the knee bearing surface [3]. By absorbing the external stress on the knee joint, the maximum load of mechanical load. At the same time joint capsule and cartilage can secrete synovial fluid, the lubrication can make the knee in the lowest wear state of the activities. At the same time, the knee joint around the knee ligament play a role in strengthening the stability of the knee. Including the prevention of the anterior and posterior cruciate ligament of the femur and the tibia, the reinforcing side of the knee joint and the tibial collateral ligament, and the front reinforcement to limit the knee flexion. Articular cavity, tibia and femur articular surface between the medial meniscus, the medial meniscus was narrow before the width of the "c" shape, the lateral meniscus was "o" shape, and with the rear of the rouge muscle bond connected, with Buffer vibration, to maintain the stability of the joints, to prevent knee cartilage injury. The normal knee range of motion includes 135 degrees "flexion to 5-10 degrees" overturned, the horizontal range of activities inward and outside the about 3 degrees [4]. 


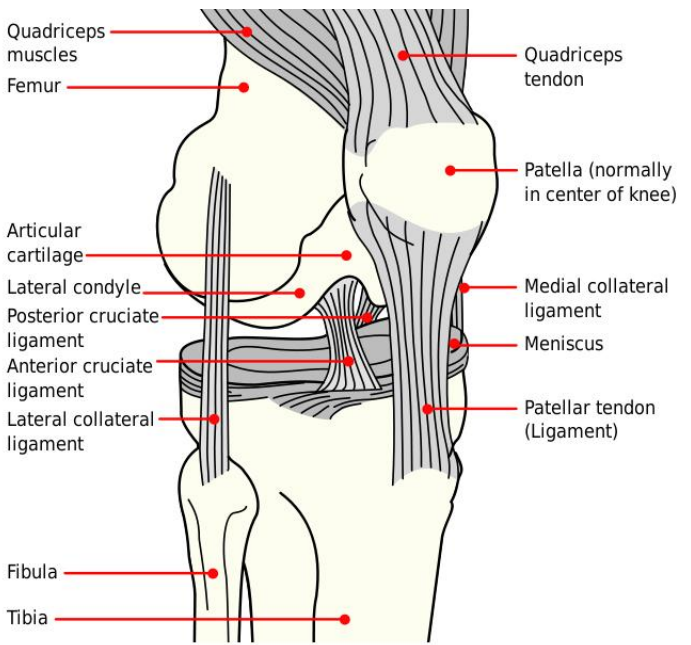

Figure 1: Anatomy of the knee

Acupuncture therapy in China has thousands of years of history, Chinese medicine, arthritis is due to qi and blood deficiency, camp health disorders, texture loose, wind cold dampness evil take the human body invasion, into the network, Blood flow is poor, evil stranded in the joints caused by joint stiffness, swelling, pain, limb flexion and extension of the long time is inside the organs, there is evidence [5]. Acupuncture treatment in the vicinity of the lesion acupoints, can stimulate the gas, dredge local meridian qi and blood, fatigue fatigue stagnation, scattered swelling and pain at the same time with the syndrome differentiation points, adjustable and health, to strengthen the removal of the joints of the cold wind Effect, so that the meridian of the meridians to be smooth, Jiedu of the bones to Shuda, not Rong of the texture to moisten. Acupuncture treatment can also be through the prescription compatibility, conditioning yin and yang, replenishing qi and blood, strong bones, adjust the organs of qi and blood function, to mobilize the body's resistance to disease, to help righting, the purpose of disease prevention and treatment $[6,7]$.

\section{INFORMATION AND METHODS}

\subsection{Research material}

In the period from March 2017 to June 2017, 86 patients underwent arthritis treatment in our hospital were divided into a total of 86 patients, including 43 patients in the experimental group and 43 patients in the control group. $(\mathrm{P}<0.05)$. There were no significant differences

Table 1: Comparison of two cases of general data

\begin{tabular}{|l|c|c|c|c|}
\hline \multirow{2}{*}{ Group } & \multirow{2}{*}{$\begin{array}{c}\text { Number of } \\
\text { cases }\end{array}$} & \multicolumn{2}{|c|}{ Gender } & \multirow{2}{*}{ average age } \\
\cline { 3 - 4 } & 43 & 26 & 17 & 57.12 \\
\hline Test group & 43 Male & Female & 59.63 \\
\hline $\begin{array}{l}\text { Control } \\
\text { group }\end{array}$ & 43 & 22 & 11 & 0.883 \\
\hline P & & \multicolumn{2}{|c|}{0.759} & \\
\hline
\end{tabular}

Table 1 results showed that the two groups of patients sex, age, by statistical tests, no significant difference $(\mathrm{P}>0.05)$, comparable.

\subsection{Research methods}

Control group: oral ibuprofen $400 \mathrm{mg}$ twice daily, methotrexate $10 \mathrm{mg}+$ $0.9 \%$ saline $20 \mathrm{ml}$ intravenously, once a week for 6 weeks. After 6 weeks of treatment, the two groups of patients with arthritis related indicators, symptom indicators, including the number of tender joints, swelling joints, morning stiffness, etc., biochemical indicators, including rheumatoid factor, C-reactive protein, ESR and other laboratory indicators Variety.

Study group: Western medicine treatment with the control group. In the western medicine treatment based on the use of acupuncture treatment, according to the Eleventh Five-Year Plan teaching materials, "acupuncture" acupoints, the main points: Dazhui, on the crystal $\mathrm{Yu}$, Zusanli, spleen, Guan Yu, Shen Yu, with points: Sanyinjiao, Hegu Yanglingquan, Qu pool and so on. Each time you choose 6-7 points, with $75 \%$ alcohol skin disinfection. Select the $25-40 \mathrm{~mm}$ needle, the needle was gas, the implementation of flattening diarrhea method, needle 20 minutes, the main point of the application of warm acupuncture every point, every 5 minutes, the next day 1 , a total of 6 weeks to complete a course of treatment The

\subsection{Evaluation index}

\subsubsection{Joint pain}

1 level: mild tenderness; 2: moderate tenderness, weight when the retraction; 3: severe tenderness, when the light pressure back to the back of the tender Shrink

2 level: the pain of patients with joint pain: according to the 4 rating: 0 level: no pain when the event; 1 : mild pain when the event; 2 : moderate pain during the event; 3 : severe pain during the event, not Dare to move. (2) Joint swelling $((0-3)$ :

Level 2: joint swelling is more obvious, swelling and bone protrusion phase, therefore, the joint around the soft tissue depression disappeared; 3 level: joint swelling, but not more than the joint near the bone protrusion; Joint height swelling, swelling has been higher than the nearby bone protrusion.

(3) Number of tender joints (months)

(4) The number of swelling joints (one)

(5) Morning morning time (minutes)

(6) Evaluation of joint pain in patients.

\subsection{Statistical method}

Using SPSS18.0. The data were processed by the software. The measurement data were expressed by the mean and negative standard deviation $(x \pm s)$, and the $t$ test and the counting data rate (\%) were used. The X2 test showed that the difference was significant Statistical significance.

\subsection{Result}

\subsubsection{Treatment}

Clinical signs of the study group and the control group after treatment to improve the indications are more obvious, but the study group of patients to improve the wish more obvious.

There was significant difference between the two groups $(\mathrm{P}<0.05)$. The patients' joint function was compared with Table 2:

Table 2: Study group and control group before and after treatment statistics

\begin{tabular}{|l|l|l|l|l|}
\hline Project & \multicolumn{2}{|c|}{ Research group } & \multicolumn{2}{c|}{ Control group } \\
\cline { 2 - 5 } & $\begin{array}{l}\text { Before } \\
\text { treatment }\end{array}$ & $\begin{array}{l}\text { After } \\
\text { treatment }\end{array}$ & $\begin{array}{l}\text { Before } \\
\text { treatment }\end{array}$ & $\begin{array}{l}\text { After } \\
\text { treatment }\end{array}$ \\
\hline $\begin{array}{l}\text { Number of } \\
\text { cases } \\
\text { (months) }\end{array}$ & 43 & 43 & 43 & 43 \\
\hline $\begin{array}{l}\text { Number of } \\
\text { tender } \\
\text { joints } \\
\text { (months) }\end{array}$ & $12.38 \pm 4.32$ & $5.78 \pm 3.86$ & $12.41 \pm 3.98$ & $8.72 \pm 6.87$ \\
\hline $\begin{array}{l}\text { Tenderness } \\
\text { index }\end{array}$ & $16.46 \pm 6.83$ & $4.86 \pm 5.23$ & $16.50 \pm 7.28$ & $9.73 \pm 3.12$ \\
\hline $\begin{array}{l}\text { Number of } \\
\text { swollen } \\
\text { joints (s) }\end{array}$ & $5.01 \pm 2.86$ & $2.13 \pm 3.78$ & $5.11 \pm 5.98$ & $3.58 \pm 5.41$ \\
\hline $\begin{array}{l}\text { Hands } \\
\text { average } \\
\text { grip }\end{array}$ & $11.25 \pm 5.49$ & $21.58 \pm 6.56$ & $11.58 \pm 6.87$ & $20.85 \pm 8.54$ \\
\hline
\end{tabular}




\begin{tabular}{|l|l|l|l|l|}
\hline $\begin{array}{l}\text { strength } \\
(\mathrm{kPa})\end{array}$ & & & \\
\hline $\begin{array}{l}\text { Morning } \\
\text { time (min) }\end{array}$ & $35+10$ & $12 \pm 4.52$ & $32 \pm 6.5$ & $22 \pm 5.36$ \\
\hline \multicolumn{5}{|l|}{ Table 2.cont } \\
\hline $\begin{array}{l}\text { Pain } \\
\text { intensity }\end{array}$ & $8.02 \pm 3.78$ & $4.12 \pm 0.87$ & $7.98 \pm 5.41$ & $6.45 \pm 5.19$ \\
\hline
\end{tabular}

Table 2 shows that joint tenderness, joint swelling, and morning stiffness time were significantly improved in both groups compared with before treatment. The treatment group was statistically significant compared with the control group before and after treatment $\mathrm{P}\langle 0.05$, $\mathrm{p}\rangle$ 0.05 , comparable.

\subsubsection{Treatment effect}

The efficacy of the two groups of patients have been improved, the study group was significantly higher than the control group $\mathrm{P}<0.05$, the two groups of treatment effect comparison:

Table 2: Comparison of the two groups of treatment

\begin{tabular}{|l|l|l|l|l|l|}
\hline Group & $\begin{array}{l}\text { Number } \\
\text { of cases }\end{array}$ & Effective & $\begin{array}{l}\text { Litter } \\
\text { Effective }\end{array}$ & Nvalid & Efficient(\%) \\
\hline $\begin{array}{l}\text { Research } \\
\text { group }\end{array}$ & 43 & 20 & 21 & 2 & 95.34 \\
\hline $\begin{array}{l}\text { Control } \\
\text { group }\end{array}$ & 43 & 15 & 26 & 10 & 76.74 \\
\hline
\end{tabular}

\section{CONCLUSIONS}

Arthritis mainly involves peripheral joints. It is a systemic inflammatory autoimmune disease, but also a major cause of disability. In recent years, acupuncture replacement therapy for arthritis has been widely publicized. Acupuncture, originated in China more than 3,000 years ago, is one of the most popular complementary replacement therapy. That is, through a fine needle insertion and operation to stimulate acupuncture points, also known as acupuncture meridian points. Acupuncture is often used in the treatment of pain-related diseases and is demonstrated by biological mechanisms. The aim of this study was to observe the clinical efficacy of acupuncture and moxibustion in patients with arthritis. Western medicine treatment of arthritis can achieve a certain effect, but with side effects. In recent years, acupuncture has been widely proved to be an effective form of treatment. Western medicine and acupuncture on the level of treatment of the disease is increasingly showing a different degree of change. In this study, we examined the clinical efficacy of acupuncture in the treatment of arthritis by observing 86 patients who received arthritis treatment from March 2017 to June 2017. The results showed that the total effective rate of the treatment group was 95.34. The total effective rate was 76.74 , the difference was significant. Acupuncture can help patients recover and may provide new arthritis treatment programs for our hospital.

\section{REFERENCES}

[1] Xiangqian, L., Gonghe, Y. 2004. Knee Joint Osteoarthritis TCM name and status of traditional Chinese medicine treatment review [J]. Chinese Journal of Orthopedics, 16 (4), 53-54.

[2] Xinmin, Q., Hongbin, L., Lingyun, F. 2007. Pharmacology and Applications Of Chinese Materia Medica. Journal of Gansu College of Traditional Chinese Medicine, 24 (4), 42-43. (in Chinese with English abstract)

[3] Zhaoxia, D. 2005. Acupoint injection in the treatment of rheumatoid arthritis clinical observation [J]. Guiyang College of Traditional Chinese Medicine, 27 (4), 30-31.

[4] Xiaoyan, W., Zheng, L. 2013. Acupuncture on rheumatoid arthritis related indicators [J]. Journal of Yunnan Traditional Chinese Medicine, $34(8), 41-42$.

[5] CMO. 2015. Knee osteoarthritis diagnosis and treatment expert consensus (2015 version) [M]. Chinese medicine orthopedic, 07, 4-5.

[6] Chongbing, L. 2015. Stimulation with warm acupuncture and moxibustion treatment of knee osteoarthritis 35 cases [J]. Journal of Practical Traditional Chinese Medicine, 01, 53-54.

[7] Zongliao, Z., Minjia, B., Yawei, W., Chenglong, L. 2014. Acupoint injection in the treatment of knee osteoarthritis 74 cases [J]. Modern Chinese Medicine, 06, 32-34. 